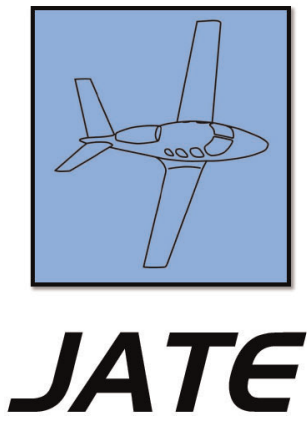

Journal of Aviation Technology and Engineering 10:2 (2021) 58-72

\title{
Qualitative Findings from the Practice of Outsourcing by the Aviation Technical Services Industry in Northern Europe: Comparison With Literature
}

\author{
Jukka Holkeri
}

Aalto University

\begin{abstract}
The outsourcing of maintenance and other technical services is a trend in both military and civil aviation. This article uses input from real outsourcing cases in Northern Europe to verify previous literature findings and to introduce new viewpoints to fill an identified research gap.

Interviews of deeply involved individuals from six cases were selected and analyzed using the Delphi method. The findings were synthesized using a framework that articulates contexts, observed outcomes, and generative mechanisms.

Many of the key literature findings were verified by this case analysis, but there were also some contradictions and new observations that had not been identified in the literature.

The chosen cases represent three aviation industry segments and a selected geographic area. Results may differ in other segments and geographies even though aviation is regarded as an international industry. The methodology applied in this paper could be replicated in other segments and areas to broaden the scope of research.

Improving understanding of the underlying processes in aviation outsourcing activities should improve efficiency and even flight safety.

This research provides a comparison between empirical cases and more academic literature and shows the clear contribution of deeper analysis to research in this field. There also seems to be a need to continue case studies to achieve a more complete picture of the subject matter.
\end{abstract}

Keywords: MRO, outsourcing, maintenance, aviation

\section{Introduction}

Aircraft operators work in a regulated environment and face increasing cost pressures. Therefore, they need to arrange technical services (often referred to as MRO-maintenance, repair, and overhaul) in a way that meets qualitative demands for the lowest cost and lowest risk. Outsourcing these services to a service provider is a commonly used alternative to performing these activities in-house. This paper aims to understand better the practice of outsourcing from both the aircraft operators' and service providers' points of view to complement literature findings. Apart from contributing to the research, the findings also provide valuable information to industry practice and planning. Chosen outsourcing solutions depend on operators' fleet size, fleet mix, etc. (Al-kaabi et al., 2007; Bazargan, 2016; De Jong \& Smit, 2019). Maintenance can be 
categorized as corrective or preventive and it can either be tied to specific times (e.g., calendar time, flight hours, or flight cycles) or take place based on the condition of the aircraft or its systems (Knotts, 1999).

The key definitions used throughout this paper are those of the operator and service provider as defined by the European Aviation Safety Agency (2017). The former is the organization that operates the aircraft and the latter is the entity that is a subcontractor providing maintenance, repair, and other technical services to enable the operator to carry out its flight activities in accordance with the regulations. In the United Sates the service providers approved by the Federal Aviation Administration (FAA) are referred to as repair stations.

Cost pressures mainly drive outsourcing, which is realized through a service provider selection process (McFadden \& Worrells, 2012; Yang et al., 2007). The portion of outsourced maintenance has been growingfrom 37 per cent in 1996 to 64 per cent in 2008 as measured by cost at main U.S. airlines (Quinlan et al., 2014). It is important to study the underlying mechanisms to understand better this essential part of the aviation industry.

Cost is only one of the key drivers for decisions while risk assessment together with compatibility is at least equally important as summarized by Holkeri (2019). AliMarttila et al. (2016) drew the same conclusions on maintenance service partner value in general. There are also many available examples (Beaumont, 2006; Erickson et al., 1997; Hsu \& Liou, 2013; Quinlan et al., 2013) that show partnership-type relationships between operator and service provider. De Jong and Smit (2019) used a game theory approach to compare a performance contract to a collaborative contract (equaling what is here referred to as a partnership) and found the latter to result in higher utility. Clarity seems to be the key success factor (KSF) in carrying out agreed work (Beaumont, 2006). Goncalves and Kokkolaras (2018) proposed a profit-sharing model for the cooperation between original equipment manufacturers (OEMs) and service providers for the ultimate benefit of the operator and the whole MRO value chain. The role of OEMs in MRO outsourcing is highlighted in the results of the current paper but is, however, not widely considered in the literature.

A literature survey by Holkeri (2019) grouped the findings using the research synthesis (CIMO) framework that is explained later in this paper and revealed a gap in the understanding of aviation MRO outsourcing research, as very little empirical case data have been analyzed and published (e.g., Canaday, 2009; Fournel, 2005; Goncalves \& Kokkolaras, 2019). Furthermore, the actual criteria for selecting a supplier of MRO services has not been explored (Demirtas, 2013). The current research helps to fill these gaps, and the studied cases provide insight into practical selection methods and criteria.
Connected also to heavy regulation and usage of public funds (e.g., in military aviation), the development of MRO outsourcing necessitates increased sophistication and control both in service provider selection and during execution (Hsu \& Liou 2013; Van Wagner, 2007) as well as constant development of regulatory oversight (Machado et al., 2016; Quinlan et al., 2014). Professional, efficient, transparent, and traceable processes are important to ensure the expected results in cost savings, to meet regulations and to ensure flight safety (Hsu \& Liou, 2013; McFadden \& Worrells, 2012). The U.S. Office of Inspector General that works under the umbrella of the U.S. Department of Transportation has noted a chronic history of inadequate FAA oversight of service providers in the United States and European Union where outsourced maintenance was performed on U.S.-registered aircraft and components. This issue has been noted also in many research papers. For example Sheehan et al. (2018) analyzed perceptions of FAA efforts in developing the oversight of service providers and found quite some issues that are now in the process of being tackled.

One possibility is that the literature findings about the outsourcing of aviation technical services are either too theoretical or too general (Demirtas, 2013; Holkeri, 2019), whereas complementing and comparing them by analyzing real cases bring a better understanding. This was in the work reported in this paper performed by asking experts their opinions and obtaining background data from persons that have been involved in outsourcing cases either on the side of operators or service providers. Based on the six case studies presented here, there are differences between the literature and empirical findings, such as service provider selection methodology and the possible continuation of growth of the outsourced portion of MRO. Several new findings were also noted, among them the way public procurement rules affect the processes and the challenges in formulating requirements to a tender document.

As the idea of this study is to verify literature findings, research question number one is formulated as follows:

\section{Research Question 1: Are the findings of the literature applicable in real cases? (RQ1)}

It is also probable that the interviews concerning real cases result in new and additional information that was not recognized in previous research. This assumption is now formulated as research question number two:

Research Question 2: Are there factors affecting the selection of an outsourced MRO service provider that have not been revealed in the literature? (RQ2)

The next section of this paper will discuss the research process and applied methods in detail. Section 3 summarizes the results of the first interview round. These 
summaries are used as input for the second interview round, the results of which are in Section 4 compared to literature findings, using the CIMO framework. Section 5 discusses answers to the above formulated research questions.

\section{Research Methods}

This study compares empirical experience from independent, practical cases with literature findings. The six real outsourcing cases from three aviation industry segments were carefully chosen so that they provided enough variety, while at the same time being comparable in volume. The operators concerned in the cases had fleets totaling some 100-200 aircraft. The chosen approach was to include both operator and service provider points of view in order to enable a comprehensive analysis of the phenomena. Even though operators make the final outsourcing-related decisions, it is also important to understand how these are experienced by service providers.

Cases were analyzed by extracting qualitative empirical information from an expert group of individuals deeply involved in the cases. Before the interviews, background studies were performed for the cases from press releases and other publicly available material. Two rounds of interviews were conducted in a manner designed to minimize the possibility of the interviewees being biased by the question formulations.

Williams (2007) provides descriptions of five different methods of qualitative research. The current approach applied elements of a case study (as it explores an in-depth program, is based on data from multiple sources, and is targeted at finding lessons learned) but also a grounded theory study (aimed at deriving general abstract theories grounded in the views of the participants). However, it could best be described as a phenomenological study (with the focus on the participants' perceptions of the event based on in-depth interviews). The summary of steps to carry out the phenomenological research provided by Groenewald (2004) was used as a baseline in this paper. The phenomenological fieldwork was structured in two interview rounds using the well-established Delphi method. Interviews were structured using questionnaires. The collected answers were arranged and structured using the research synthesis (CIMO) framework as presented by Van Aken et al. (2008). Within this phase, the themes that were most often referred to were judged to form the key results of this research. The process is described in Figure 1.

\subsection{Cases}

The selection, definition, and description of the cases were realized using literature or public domain information with the facts checked in the interviews. An obvious limitation was the limited availability of non-confidential information, leading to exclusion of some potential cases. Equally, there was a need to find suitable interviewees, who would be able to enter into detailed and deep discussions instead of only providing superficial, commonplace information. Comments were collected for possible differences from published information. The focuses in this phase were the scope, duration, and volume of the outsourcing, financial implications to both operator and service provider, as well as the choice between an open competition and a direct negotiation process.

The cases were targeted to represent different areas of aviation where known outsourcing has occurred in Northern Europe. A total of six cases were studied with a target to include views from both operator and service provider sides.

Three cases represent approaches to military helicopter technical services outsourcing in three different Nordic countries-Finland, Sweden, and Denmark. In the Finnish case, the helicopter type was the NH90 and the outsourcing took place in 2010. Black Hawk support tender was conducted in Sweden in 2014 and a discontinued competition for Danish military helicopter maintenance in 2005. Two cases were studied from airlines. Finnair outsourced their engine maintenance in 2012 and Flybe outsourced their line maintenance in Birmingham in 2013. Finally, a case for outsourcing elementary military flight training and related MRO support in Finland in 2005 was analyzed.

\subsection{Delphi Method}

The collection of data was structured using the Delphi method. As defined by Linstone and Turoff (2002, p. 3), "Delphi may be characterized as a method for structuring

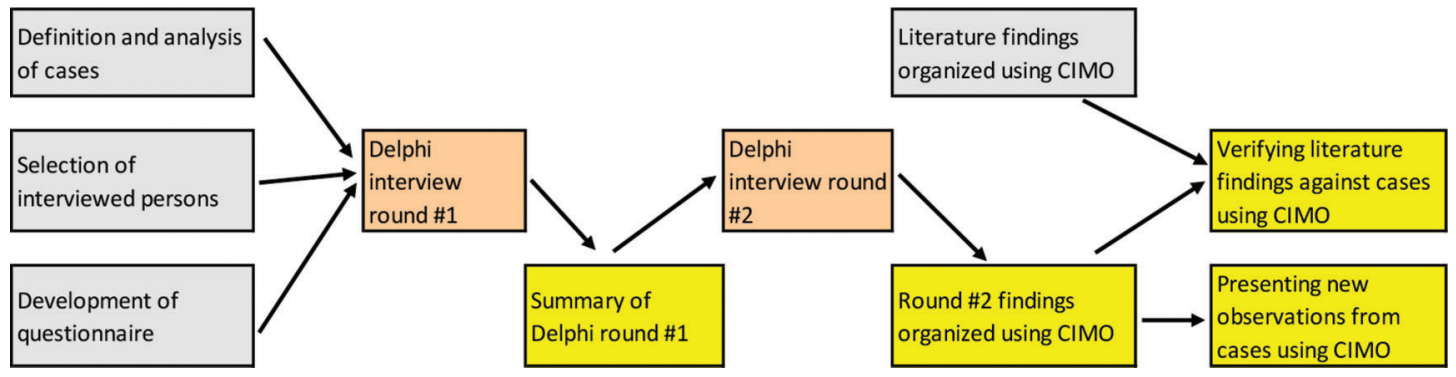

Figure 1. Research process. 
group communication processes so that the process is effective in allowing a group of individuals, as a whole, to deal with a complex problem."

In Delphi, interviewed persons are recognized as experts in their field of expertise and asked to give their futureoriented estimations about the development of a certain matter (Sivelius, 2001). However, in Linstone and Turoff (2002, pp. 3-4), the authors widen this as follows: "While many people label Delphi as a forecasting procedure because of its significant use in that area, there is a surprising variety of other application areas. Among those already developed we find: 'Gathering current and historical data not accurately known or available...' [list continues].”

The method applied here is the traditional "Delphi exercise" (Linstone \& Turoff, 2002) and it has four typical and distinct phases (Sivelius, 2001): (1) exploration of the subject under discussion, (2) reaching an understanding of how the group views the issues as determined here by the first round of interviews and subsequent analysis of the results, (3) significant disagreement is explored and reasons determined, which is now conducted through a second round of interviews, and (4) a final evaluation when all information has been gathered and analyzed, which is conducted using the research synthesis (CIMO) approach.

In the current study, the interviews were used both to verify earlier literature findings in the chosen three industry segments and to complement them with new observations. The interviewed experts were asked questions about a real case that was specifically selected for each, and also more general questions regarding the development of outsourcing in the future. The first Delphi round results were summarized and the result was transferred into a second round of interviews to check and further clarify the findings. This is the stage within the Delphi method when the interviewees become aware of each other's combined views. However, the additional viewpoints of other experts may alter their opinions and revoke new important comments. The Delphi method was applied in this research for interviews using open questions to let the interviewed experts' views be expressed in an unbiased form.

\subsection{Interviews}

The interviewees held senior positions in respective organizations at the time of the outsourcing decision process and were closely working in (and in most cases in charge of) the outsourcing process within the cases (on either operator or service provider side). There was a conscious choice to involve senior management in order to ensure a wider perspective compared to interviewing lowerlevel persons without an overall understanding. Table 1 shows the division of interviewed experts between cases and operators versus service providers as well as indicating where documentation describing the case and requirements was available. Some of this documentation was not public, and was provided solely for the purposes of this research work.

Each in-depth interview lasted about one hour and the theme was handled extensively, complementing the answers to the questionnaire with plenty of background information and assessments.

The same questions were used for all respondents. Both case-specific and general views were collected in round 1, whereas round 2 concentrated on general and industry segment-specific issues without connecting them directly to the cases. The questionnaire based on the guidelines of Groenewald (2004) and Lietz (2010) for Delphi round 1 is presented in Appendix 1. It encouraged the respondents to widely express their views about each subject.

The Delphi method's key intent is to extract free opinions from an expert panel. Several possible pitfalls were noted by Linstone and Turoff (2002) and the difference between research questions and the questions asked of participants was discussed by Groenewald (2004). These views were considered when designing the interviews. In practice, the approach was to avoid such questions that would typically just lead to the interviewee either confirming or denying a concept derived from the literature by answering yes or no. The aim was to build questions that urge descriptions of phenomena, opinions, and experiences. The questions proceeded from general to more specific, vague quantifiers were avoided, and the sequence of questions was carefully considered as suggested by Lietz (2010). This also helped in the collection of data for inspecting RQ2 (Are there factors affecting the selection of an outsourced MRO contractor that have not been revealed in the literature?).

A total of ten individuals were interviewed in the first Delphi round. Additionally, in three cases, the documentation specifying the outsourcing case (request for quotation,

Table 1

Interviewed persons by case and background as well as request documentation connections.

\begin{tabular}{lccc}
\hline Case & Operator & Service provider & Request documentation \\
\hline Military helicopter 1 & $\mathrm{X}$ & $\mathrm{X}$ & $\mathrm{X}$ \\
Military helicopter 2 & & $\mathrm{X}$ & $\mathrm{X}$ \\
Military helicopter 3 & $\mathrm{XXX}$ & $\mathrm{X}$ & \\
Airline 1 & $\mathrm{X}$ & & $\mathrm{X}$ \\
Airline 2 & $\mathrm{X}$ & $\mathrm{X}$ & \\
Military training & & & \\
\hline
\end{tabular}


RFQ) was available for analysis. These were considered parallel to the interview answers. In the second round, eight out of the original ten persons were able to participate. In line with the principles of the phenomenological methodology, the limited number of interviewees was well compensated by their seniority and experience, combined with the long and thorough interview sessions.

The interviewed persons were contacted well in advance of the interview time and the questionnaire was also submitted to them prior to the actual interview. The first round of interviews was conducted between April 2014 and February 2015 one at a time. The second round took place between May 2016 and November 2017.

In the beginning of each interview, the aims of the research were summarized to the interviewee with the setup and methodologies being explained (Groenewald, 2004). These included that the collected data would be stored, the intention was to collect trends through summaries and not to focus on individual opinions, and no direct quotes with names would be made unless specifically agreed upon as well as that the author-interviewer remains neutral and does not add opinions or data despite possibly having background knowledge of the cases from other encounters.

It was often very hard for the interviewees to quantify the effect of each separate criterion or other factors in the outsourcing decision process. Often these are also regarded as trade secrets-the exact distribution of weights of parameters is not public information.

All personal interviews were recorded with the individual's permission. At the same time, written notes were made during the discussion. Some interviewees had already filled in parts of the questionnaire in writing beforehand. These answers were discussed during the actual interviews to assure a mutual understanding. Unless there was something that needed clarification, the pre-written texts were used.

\subsection{Analysis of the Results}

An analysis of the RFQs produced results in the fields of the indicated selection criteria and their weights, descriptions of the rationale for outsourcing, and key performance indicators for successful service. When combined with the interviews, some unclear or contested requirements were also revealed.

The data were compiled by collecting the answers of each case into one table following the guidelines of Groenewald (2004). The tables were written in English, although some interviews were conducted in Finnish. The translation was conducted by the author. The translation has a slight risk of change of the intent of the interviewee. However, verification was possible from both the stored written notes and the recordings.

The answers from round 1 interviews were arranged and collected under common themes, which were subsequently formulated as concepts with some background text. This formed the collection of concepts summarized in Section 3 of this paper.

\subsection{Coding}

DeCuir-Gunby et al. (2011) stated that codes are created from three major drivers: theory, data, and research goals. In this paper, the coding is theory-driven and based on literature findings and more specifically those presented by Holkeri (2019). The findings of Weston et al. (2001) concerning reciprocity between coding development and the evolution of understanding the phenomenon were also noted. What was really the true informative content of the answers sometimes changed during this evolution beyond the first, simple answer to each question.

The responses in round 1 were summarized into a table and grouped by cases. They were then color-coded based on how well they confirmed the literature findings (RQ1) or whether they provided new information (RQ2). The reliability of the coding was also evaluated (DeCuir-Gunby et al., 2011).

The round 2 answers were collected into a table format and interpreted either to support the given concepts or to disagree with them. In situations where the respondent did not have a clear position, the answer was regarded as neutral. A compilation of this is shown in Appendix 2. The coding was thus YES/NO/NEUTRAL.

\subsection{Research Synthesis}

As described in the introductory section of this paper, the outsourcing process can be rather complex in the aviation industry with many factors to be taken in account simultaneously. Research synthesis (CIMO logic) was chosen as the theoretical framework best suited for this study to arrange expert opinions in a structured manner. This framework helps to understand the process of aviation MRO outsourcing, by sorting the findings accordingly. Previously the research synthesis was used in Holkeri (2019) to structure literature findings around the same subject area, facilitating therefore also the intended comparison between literature and interview findings. Van Aken et al. (2008) summarize the research synthesis and the CIMO logic as follows: "In this class of problematic Contexts (C), use this Intervention (I) type to invoke these generative Mechanisms (M) to deliver these Outcomes (O)."

The application of the CIMO and categorization of findings into the four elements follows here the guidance given in Van Aken et al. (2008). The Context (C) is generally aviation technical services or in a selected operator segment.

At least two possible ways of dividing findings between Intervention (I) and Mechanism (M) could, however be 
identified. In this paper, the categorization is conducted in the same way as in Holkeri (2019). Namely, Intervention (I) refers to optimizing the outsourcing process to obtain the desired result, where the selection criteria used by the operator is often a key element. Likewise, the applied process to select the service provider or to keep the work in-house is in the Mechanism (M). This can be regulated, like in public procurements, or tailor-made for only one case or something in between such as a company policy. Another option of the CIMO application could be to regard the Intervention (I) simply as the decision to outsource and group the outsourcing process optimization and execution under the Mechanism (M) element. The first mentioned application method was chosen to enable better identification of the possible practical factors and/or boundary conditions affecting the process. In this way, these are not easily mixed with deliberate optimizing choices.

The desired Outcome $(\mathrm{O})$ of an outsourcing exercise is the achievement of the objectives of the operator (such as a cost reduction). From an industry-wide perspective, the Outcome is also the quantitative and qualitative development of outsourcing activities.

\section{Summary from the First-Round Interview Results}

First-round interviews were summarized to reflect general trends in a free verbal format. They are below arranged and summarized using the sequence of the CIMO logic (Context; Intervention; Mechanism; Outcome) explained in Section 2.6.

There are visible differences by industry segment; at least between the three segments analyzed in this study. For example, the fleet size and composition seem to have quite a strong effect on outsourcing decisions in airlines (see also Al-kaabi et al., 2007), whereas these factors have a smaller effect for military helicopters and were not mentioned in the military training segment.

Legacy mindsets and ways of working prohibit development, especially within the military training and airline segments. Declining to even consider outsourcing line maintenance (meaning daily maintenance operations) is a typical example of a legacy mindset found in several interviews. Line maintenance is traditionally kept in-house (see also Al-kaabi et al. (2007) as well as McFadden \& Worrells (2012)) but there are exceptions. However, some respondents indicated that they would not exclude more line maintenance outsourcings in the future.

OEMs seem to control the outsourcing cases in various ways-mainly driven by their desire to direct the aftermarket business to themselves and/or to their selected partners. They have means to affect operators' choices of service providers through factors such as data access, spare parts pricing, and authorizations. Increasingly, OEMs are also themselves service providers and even tie their MRO offering to the initial procurement contract of aircraft with lucrative terms. The OEM's role is strongly felt in the military helicopters and airlines segments. This is line with the statement of Goncalves and Kokkolaras (2019) that OEMs only consider their own interest currently, without really seeing the benefits of partnering with service providers. Their study does not, however, indicate the strong influence of OEMs on service provider selection carried out by operators.

Outsourcing is used for various purposes and not only to reduce costs. This is a wider scope compared to cost typically mentioned as the only driver in the literature (e.g., McFadden \& Worrells, 2012; Yang et al., 2007). Using findings of Ali-Marttila et al. (2016), it could also be possible to categorize the operators into basic-, quality- and collaboration-oriented ones related to what value they are mainly seeking from the outsourcing. However, it has become obvious that in most cases, price/cost is the ultimate factor when making final decisions between the few remaining bidders that fulfill other criteria.

The development of one's own operation is a viable option for outsourcing and the perceived loss of an operator's own technical competence is a major fear that slows down outsourcing. This fear is mainly connected with loss of control in safety-critical issues, as the operator is ultimately responsible for the aircraft being safe to fly.

Strong support was received for the KSFs of technical services outsourcing being tied to cooperation (clarity, commitment, and joint working). The importance of the relationship between service provider and operator has been increasing and a cultural match between them is the key to success both in the selection phase and in the success of achieving the intended goals in the airlines segment. In practice this means the need to understand on both sides what has been agreed and to establish a working relationship. Those that were critical towards this element pointed out that openness, at least in the bidding phase, was not common practice.

According to most answers, the selection criteria vary based on the fleet mix (especially the age or maturity of equipment) and the business concept (such as if the operator is flying mainly from one or several home bases or if the operator has a large amount of capital tied to the equipment opposed to renting it); however, some respondents did state that the criteria are similar regardless of the fleet parameters or the operator. In addition, newly introduced systems provide a different outsourcing case from established ones. Availability of the fleet is a key criterion and it will continue to develop in the future to measuring and agreeing goals for mission performance of the equipment in question.

Risk-related factors (e.g., capability and delivery performance) have become items that service provider candidates need to master in order to be considered and they are no longer areas of differentiation. Risks and relationships are emphasized in the two military segments and cost is 
typically a factor coming from legislation and given budgets. Legislation directs publicly funded operators (such as militaries) to comply with public procurement rules that in the minds of the interviewees do not always lead to the best and desired solution-for example, to create a long-term partnership. National security reasoning in some areas may be a way to circumvent the cost-focused processes in military aviation MRO outsourcing. In the airlines segment, the risk and relationship areas are approached by minimum levels that need to be met by the service provider to qualify for the actual decisive cost comparison. This is somewhat contradictory to the findings of Hsu and Liou (2013) and Ali-Marttila et al. (2016), who claim that risk and relationship are ultimately the most decisive factors in service provider selection. Sheehan et al. (2018) point out that failed oversight on maintenance practices eventually puts more pressure on the operator, possibly even mitigating some of the gained cost savings. Many respondents also noted the increasing role of sustainability and corporate social responsibility (CSR) in different forms in the future even though these are not yet essential differentiating factors.

Furthermore, the development from short, one-time, contract-based transactions to more permanent partnerships between parties was considered a trend and a clear desire from both operators and service providers. Such a development stresses the growing importance of a good relationship between operator and service provider. Despite this, legislation in public procurements (especially the need for frequent and regulated competitive bidding) and, in some cases, financial restrictions force operators to become involved in more spot-deal-like agreements.

Clear interview support was noted for a two-step approach in supplier selection, although exceptions using only one step do exist. In many named cases, the first selection round is focused on nonfinancial areas (risk assessment, relationships) and the second and final round selects the winner by cost from those that succeeded in the first round. The role of cost is still very dominant in final supplier selection.

Both subjective and objective criteria are used, which confirms that the selection processes include human evaluation elements and are not just mathematical models or sets of rational, qualitative measurements. In other words, human factors and subjectivity play an important role in the selection.

The more advanced analysis methods for selecting MRO service providers are often discussed in the literature (e.g., Cao \& Wang, 2007; Hsu \& Liou, 2013) but were not recognized in practical life. Interrelationships between the criteria were noted in some answers but no practical applications were found. Generally, the evaluation is a simple exercise of adding points together, and in some advanced cases, the results of evaluating diverse criteria are turned into monetary values (euros or dollars) for an overall cost-based comparison. This is in line with the observations of Tenhiälä (2011), who studied planning methods in manufacturing operations. Maintenance operations are easily comparable to Job Shops, for which a simpler planning method like rough-cut capacity planning is the best fit according to Tenhiälä (2011) instead of more complex methods, even though these more complex methods are often recommended in theoretical literature.

According to some comments, the buyers' capabilities and competencies to carry out the service procurement process are often limited. Furthermore, transforming an operator's qualitative and subjective desires and needs (such as cultural match) to exact and measurable requirements in an RFQ is considered a difficult task. Openness and clarity of the RFQ are also commonly considered desirable but they are not always achieved. De Jong and Smit (2019) have discussed in length the differing interests between operator and service provider. Legislation forces public operators to prepare clear RFQs and leads to price being the dominating factor for the selection criteria, as it is mostly considered the ultimate clear criterion.

Some of the respondents were quite in line with the growing trend of MRO outsourcing that was also found in the literature (e.g., Al-kaabi et al., 2007; Holkeri, 2019; McFadden \& Worrells, 2012). However, there were also comments noting an opposite trend of insourcing some work back to the operator or comments that the volume of outsourcing has already stabilized to a certain level.

According to respondents, outsourcing often brings more efficiency. This may result from the fact that MRO usually is the core activity of the service provider, while it has typically only a supportive role within the operator's organization.

In summary, the above discussed key first-round results are listed below grouped under the CIMO headings and divided between those identified in the literature and new findings. These were presented to interviewees during the second round of interviews.

Interview findings related to items found in the literature:

Context

- Line maintenance is kept in-house

- Criteria vary per fleet mix and business concept

Intervention

- Cost is the ultimate decision factor but other reasons for outsourcing also exist

- Capability and performance are not differentiating factors

- The role of CSR is increasing

- Industry segment differences exist

Mechanism

- A two-step supplier selection process is common

- Both subjective and objective criteria are used 
- Analysis is commonly conducted simply by adding points together

Outcome

- MRO outsourcing is growing

- Cooperation is a KSF

- Development from contracts towards partnerships

- Importance of the relationship grows.

New findings from the first round of interviews that were not identified in the literature:

Context

- OEMs control much of the outsourcing business and affect the choices

- Losing an operators' own technical competence is a major fear that slows outsourcing

- Legacy mindsets and ways of working are among the biggest obstacles for efficient outsourcing

- Newly introduced systems set up a different outsourcing case compared to established ones

Intervention

- The development of one's own operation is a viable option for outsourcing

- Availability is a key criterion and it will develop in the future for mission performance

- CSR is considered a good target and no failures are allowed; however, nobody is prepared to pay extra for it

- Cultural matching is very important between operator and service provider

Mechanism

- The definition of RFQ requirements is hard

- Buyers' capabilities and competencies to carry out the process are often limited

- Openness and clarity of the RFQ are desirable but not at all always achieved

- Legislation forces public operators to prepare clear RFQs and leads to the domination of price as the selection criteria
- Human factors and subjectivity play an important role in selection

Outcome

- Outsourcing often results in more efficiency.

\section{Round 2 Results: Literature and Case Study Comparison Using CIMO as Well as New Observations}

Results from the second round of interviews are discussed using the CIMO logic. The comments by respondent compared to first-round results (as presented above) are presented in Appendix 2. Subsequently, these results were grouped by the author under the CIMO categories: Context, Intervention, Mechanism, and Outcome.

Holkeri (2019) compiled literature findings and arranged them using the CIMO logic. Concepts from that paper were used now as the literature reference and compared to the results of this case study in the tables. The first columns in the following tables list the findings as presented and numbered by Holkeri (2019). The second columns present the related findings of this case research concept by concept. Finally, in the third columns, these two are compared to build a conclusion and to determine how well the case studies support the literature findings.

\subsection{Context}

It is obvious that there are several factors affecting the outsourcing decision and these result in differences between industry segments. For the Context area two out of three concepts listed in the literature were confirmed in interviews-marked C2 (line maintenance is kept in-house) and C3 (fleet size, mix, etc., impact outsourcing decision making) in Table 2. As an example: If the fleet of a certain aircraft type is small and/or the planned timeframe for using it is short, an operator may not want to tie capital itself to establish MRO capability, resulting to outsourcing. An additional factor, the position of aircraft type in its life cycle, was also seen

Table 2

CIMO/Context results from the round 2 interview compared to literature findings.

\begin{tabular}{llc}
\hline Holkeri (2019) & Case study results & Conclusion \\
\hline $\begin{array}{c}\text { C1 Modern airliners need less maintenance } \\
\text { and maintenance is split into smaller tasks }\end{array}$ & No mentions & Statement not recognized in the case study \\
C2 Line maintenance is kept in-house & $\begin{array}{c}\text { Traditionally, line maintenance is in-house. } \\
\text { Some cases and thoughts about outsourcing } \\
\text { exist }\end{array}$ & $\begin{array}{c}\text { Line maintenance may be outsourced in the } \\
\text { future but it was confirmed that it is currently } \\
\text { still mainly kept in-house }\end{array}$ \\
$\begin{array}{c}\text { Cervice provider selection varies based on } \\
\text { the fleet's/type's position in the life cycle } \\
\text { and business model impact outsourcing } \\
\text { decision making }\end{array}$ & $\begin{array}{c}\text { Differences recognized between civil and } \\
\text { military segments }\end{array}$ \\
& $\begin{array}{l}\text { Newly introduced systems set up a different } \\
\text { outsourcing case than established ones }\end{array}$ & $\begin{array}{c}\text { Fleet size and composition have a confirmed and } \\
\text { strong effect on outsourcing decisions in } \\
\text { airlines. Life cycle position is the key in } \\
\text { military decisions }\end{array}$ \\
\hline
\end{tabular}


to have an effect. This is connected to how much data there are of maintenance needs, how established are the current MRO activities, and so on. However, according to the interviews, the changes in airliner maintenance needs and plans were not considered decisive in outsourcing decisions. The respondents also added a possible future change trend to the current situation of keeping line maintenance in-house.

A new observation compared to the literature (Holkeri, 2019) was that OEMs control much of the outsourcing business through pricing of spare parts, training, and documentation. OEMs also affect the available choices through authorizations that are often mandatory in civil aviation and respected also in military aviation. An additional clarification for the development of outsourcing noted that legacy mindsets and ways of working seem to be among the biggest obstacles for efficient outsourcing together with the fear of losing operators' own technical competence.

\subsection{Intervention}

Contrary to the literature, cost still seems to remain the ultimate decisive factor when choosing a service provider even though factors related to a good relationship between operator and service provider were also confirmed to be essential (see Concept I1 in Table 3). The dominating role of cost may even have been so obvious that it has dropped from the focus of theoretical research.

CSR is becoming an important area in service provider selection even though it was not recognized in the literature.

The interviews resulted in differing views in two areas. (1) The Delphi round 1 statement that the definition of RFQ requirements is hard may be connected to the maturity of the operator organization in outsourcing activities and was not agreed by all interviewees. (2) The statement that one's own development of operations is a viable option to outsourcing seemed to be also somewhat case-specific. For instance, in some cases, operators' own development was excluded as an alternative by factors not directly related to the outsourcing analysis. An example of this was an inability to increase the number of personnel in an operator's payroll, resulting in outsourcing being the only viable option for growth.

\subsection{Mechanism}

Practical cases seem to be more straightforward than the processes and methodologies presented in the more theory- and optimization-focused literature as seen in M1 in Table 4. The usual two-step method and implementation of both objective and subjective criteria were confirmed (Concepts M2 and M3).

\subsection{Outcome}

Somewhat surprisingly, the interviewees were not in agreement about the growth of outsourcing in the airline industry and instead stated that outsourcing volume was stabilized at the current level; military segments still have growth potential (Concept O1 in Table 5). This may also be a timing issue, if the airlines' outsourcing already had reached its maturity stage after most of the research in the literature was performed. Clarity was confirmed to be a KSF (O5). Moving from individual contracts to more partnerships between operators and service providers seems to be the trend (O7). However, the interviews revealed that there are restrictions that slow down this development, especially public procurement regulations that require competition and limit the length of contracts. This finding seems to be clearly a contribution resulting from studying also the service provider view, whereas most of the literature focuses on operator views only. Some of the literature findings did not come up at all in the interviews. Worth mentioning is Concept O2 ("Control of technical services providers needs to be improved as rising levels of outsourcing may even increase the risk of accidents") based on several papers and public investigations in the USA-but does not seem to be at all a problem in Northern Europe.

Table 3

CIMO/Intervention results from the round 2 interview compared to literature findings.

\begin{tabular}{lll}
\hline Holkeri (2019) & Case study results & Conclusion \\
\hline $\begin{array}{l}\text { I1 Risk assessment and compatibility/relationship } \\
\text { are key to selection followed by cost and } \\
\text { flexibility in billing }\end{array}$ & $\begin{array}{c}\text { Cost remains the main criterion for choosing the } \\
\text { service provider, but the weight of the } \\
\text { relationship and cultural match between operator } \\
\text { and service provider have been increasing } \\
\text { Capability and delivery performance are no } \\
\text { longer differentiating factors } \\
\text { confirmed, but cost as the ultimate decision } \\
\text { factor is contrary to the literature findings }\end{array}$ & $\begin{array}{l}\text { The importance of the relationship was } \\
\text { N2 Offshore outsourcing supplier criteria: } \\
\text { low labor costs, no linguistic barriers, } \\
\text { open business environment }\end{array}$ \\
\hline
\end{tabular}


Table 4

CIMO/Mechanism results from the round 2 interview compared to literature findings.

\begin{tabular}{llc}
\hline Holkeri (2019) & Case study results & Conclusion \\
\hline $\begin{array}{l}\text { M1 Interrelationships between the criteria and } \\
\text { the changing business environment need to } \\
\text { be considered }\end{array}$ & $\begin{array}{c}\text { Evaluation in service provider selection is } \\
\text { mostly a straightforward accumulation of } \\
\text { points and no sophisticated formulae are used }\end{array}$ & $\begin{array}{c}\text { The need to consider interrelationships was not } \\
\text { confirmed in case studies }\end{array}$ \\
$\begin{array}{c}\text { M2 Two-step method: (i) screening and } \\
\text { (ii) final selection }\end{array}$ & $\begin{array}{c}\text { Service provider selection typically } \\
\text { occurs in a two-step approach }\end{array}$ \\
$\begin{array}{l}\text { M3 Both subjective and objective criteria } \\
\text { and both process variables and outcome }\end{array}$ & $\begin{array}{c}\text { Both subjective and objective criteria are used } \\
\text { variables }\end{array}$ & Subjective and objective criteria confirmed \\
& important role in selection & \\
\hline
\end{tabular}

Table 5

CIMO/Outcome results from the round 2 interview compared to literature findings.

\begin{tabular}{|c|c|c|}
\hline Holkeri (2019) & Case study results & Conclusion \\
\hline $\begin{array}{l}\text { O1 Technical services outsourcing in the airline } \\
\text { industry is growing }\end{array}$ & $\begin{array}{l}\text { Outsourcing is still growing in military } \\
\text { segments but the level has stabilized in } \\
\text { the airline segment }\end{array}$ & $\begin{array}{l}\text { Outsourcing growth has declined in airlines, } \\
\text { but growth is still recognized in the military }\end{array}$ \\
\hline $\begin{array}{l}\text { O2 Control of technical services providers needs } \\
\text { to be improved as rising levels of outsourcing } \\
\text { may even increase the risk of accidents }\end{array}$ & No mentions & Statement not recognized in the case study \\
\hline O3 Military is seeking civil methods & No mentions & Statement not recognized in the case study \\
\hline $\begin{array}{l}\text { O4 Outsourcing is used for many purposes } \\
\text { and not solely for cost reduction }\end{array}$ & $\begin{array}{l}\text { Total cost is a driver, but lack of resources } \\
\text { and competence also initiates outsourcing }\end{array}$ & Many reasons for outsourcing confirmed \\
\hline $\begin{array}{l}\text { O5 Clarity (goals and obligations), commitment, } \\
\text { and joint working are KSFs }\end{array}$ & $\begin{array}{l}\text { Risk and relationship are emphasized as } \\
\text { KSFs in the military, while in the airline } \\
\text { segment, the risk and relationship areas } \\
\text { are approached by minimum levels that } \\
\text { need to be met. The KSF in outsourcing } \\
\text { is cooperation }\end{array}$ & $\begin{array}{l}\text { Confirmed that clarity, relationships, and } \\
\text { cooperation are KSFs }\end{array}$ \\
\hline $\begin{array}{l}\text { O6 Outsourcing corresponds to low technical } \\
\text { delays }\end{array}$ & No mentions & Statement not recognized in the case study \\
\hline $\begin{array}{l}\text { O7 Development from contractual to } \\
\text { partnership-based relationships }\end{array}$ & $\begin{array}{l}\text { Trend is from short, one-time, transactional } \\
\text { cases to more permanent partnerships, but } \\
\text { legislation in public procurements and } \\
\text { financial/benchmarking needs results in } \\
\text { frequent procurements in practice }\end{array}$ & $\begin{array}{l}\text { Confirmed with the addition of regulations } \\
\text { slowing down development in public } \\
\text { procurements }\end{array}$ \\
\hline
\end{tabular}

\subsection{Literature Concepts Confirmed by Case Studies}

The Concepts that are recognized by both the literature findings in Holkeri (2019) and the case studies in this research are:

C2 Line maintenance is kept in-house

C3 Fleet size, mix, share of leased aircraft, and the business model impact outsourcing decision making

I1 Risk assessment and compatibility/relationship are the key to selection followed by cost and flexibility in billing

M2 Two-step method: (i) screening and (ii) final selection

M3 Both subjective and objective criteria and both process variables and outcome variables

O4 Outsourcing is used for many purposes and not solely for cost reduction

O5 Clarity (goals and obligations), commitment, and joint working are KSFs
O7 Development from contractual to partnershipbased relationships

\section{Discussion}

Research Question 1 was formulated as: Are the findings of the literature applicable in real cases? (RQ1). As shown above in this paper, many of the statements identified in the literature were also confirmed by the interviews. These include the impact of different parameters (such as the fleet size and business model) to outsourcing decision making, line maintenance being kept in-house, the two-step process in service provider selection, the observation that there are both objective and subjective criteria in the selection process, the importance of clarity and joint working as $\mathrm{KSFs}$, as well as the aspired development from contractual to more partnership-based relationships.

However, some literature findings were not found to be applicable based on the interviews. The strongest difference 


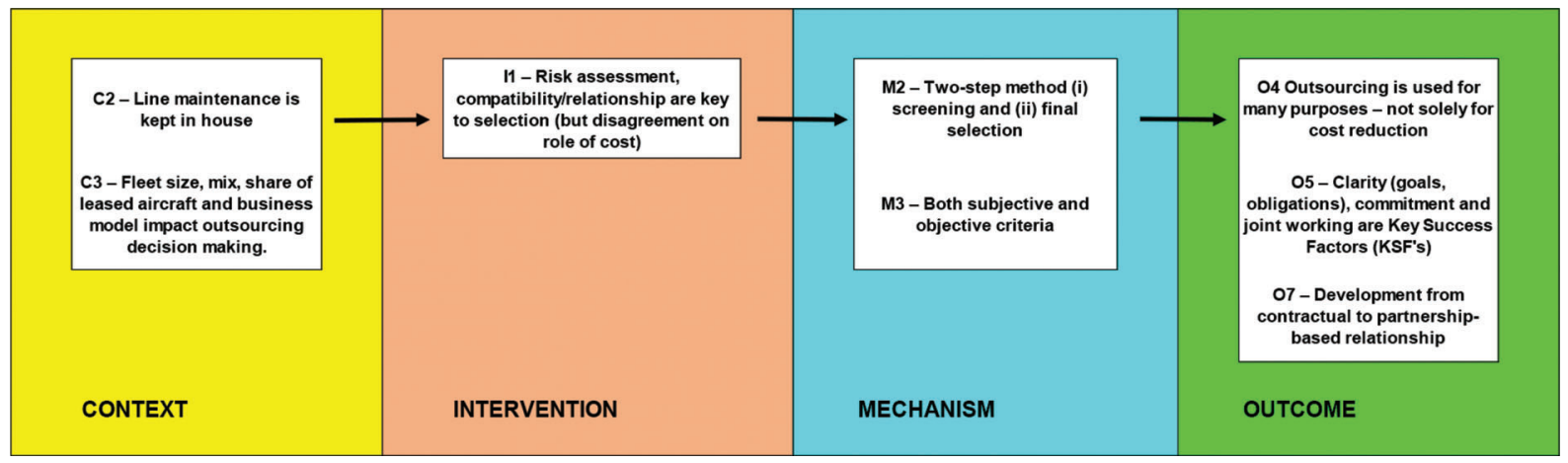

Figure 2. Concepts confirmed both by the literature and case studies using the CIMO framework.

was found in the evaluation method in the service provider selection process. It seems that the approach taken in the literature in building complex and dynamic interrelationships between selection parameters is far from the straightforward approach taken in the studied cases. An important observation was that contrary to the literature, the ultimate decision parameter for service provider selection still seems to be cost. Also, the strong growth of outsourcing in the airline industry described in the literature seems to be stabilized based on the interviews.

Additionally, some statements from the literature were not at all recognized in the interviews. It is not clear whether they are just less important or not relevant at all.

Figure 2 shows the literature Concepts confirmed in this case study arranged in a CIMO sequence.

Research Question 2 sought to pick new observations and was formulated as: Are there factors characteristic of the aviation technical services outsourcing or items affecting the selection of an outsourced MRO service provider that have not been revealed in the literature? (RQ2).

As can be noted from the summary at the end of Section 3 , some quite new findings were recorded in the "Intervention" and "Mechanism" phases of the CIMO logic. This confirms the original hypothesis of these areas representing a research gap in the literature compared with industry practice.

When new systems begin operating (e.g., within the first year) and are used, there is often no established support compared to the support available for older systems. If the whole aircraft type is new, there are no collected supportability data either. This creates both freedom and risks in forming new solutions. However, outsourcing the maintenance of systems where a long experience has been already collected (and is based on facts) is thus a lower-risk effort to both sides (provided that the data are available). Gains compared to one's own operations are achieved by rearranging the operation, which is sometimes hard. The new versus old system difference seems to be applicable in the two military contexts, but not in airlines where an increased overall efficiency was noted. New criteria for measuring service provider performance (such as availability and mission performance) seem to be only in planning in the military helicopters context.

The key role of OEMs in all outsourcing and the limiting nature of legislation in public procurements were clearly new observations that were not addressed in the literature. In the future, CSR is expected to grow into a similarly important role and CSR is becoming more of an area where the supplier is not allowed to fail. On a more subjective side, the legacy ways of working and related fear of losing one's own competence have limited the growth of outsourcing.

Forms of outsourcing and selection criteria are continually developing to a direction where the service provider is taking more and more responsibility regarding the operator's ability to perform its mission. Typically, this also indicates a wider work scope in the outsourced arrangement towards the total responsibility of the aircraft or helicopter in the technical sense.

The cultural match of operators and service providers was brought up surprisingly often, especially in the context of airlines. It is extremely hard to turn a generic wish in this area into measurable metrics in the selection process. This is maybe the best example of a challenge that is connected with the new finding that the definition of RFQ requirements is sometimes hard.

Handicaps in mastering the strictly structured tender process are noted in the interview responses. It seems that a truly organized way of outsourcing in aviation is rather new and often poorly developed. Public procurement regulations add complexity with their requirements for openness and a lack of possibilities for subjective decisions. There is no objection to the desirability of openness and clear structure, but there are doubts about the integrity of implementation on both the operators' and service providers' sides.

Figure 3 illustrates using the CIMO framework the new findings of this study that were not identified in the literature. 


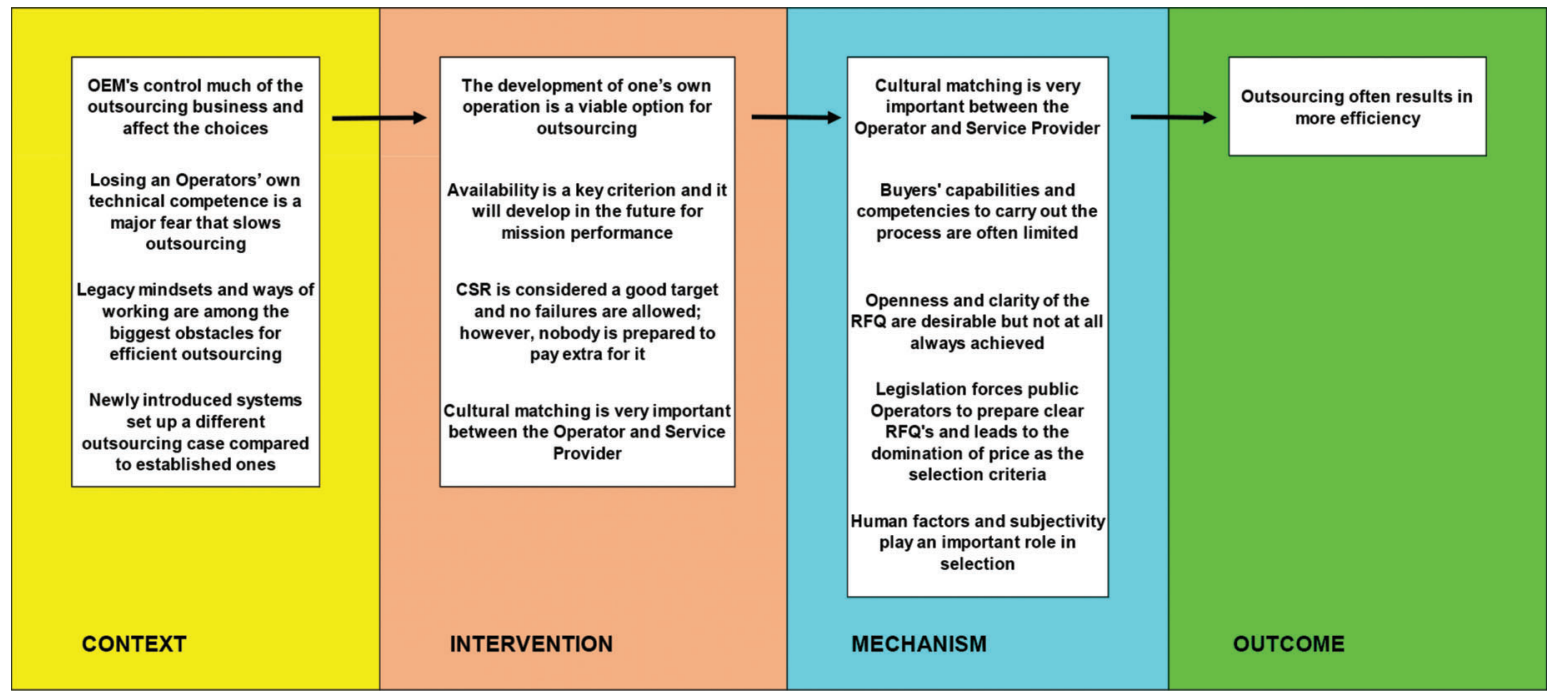

Figure 3. New concepts found in case studies using the CIMO framework.

\subsection{Limitations and Further Research}

Despite the tangible results, the obvious limitation of this research is the choice of cases. For example, there are other aviation industry segments and other areas where the results might differ. However, aviation is already a global industry with regulated processes and similarities covering most countries, service providers, and operators, which greatly reduces the limiting effect. Further research paths could dig deeper into the differences between industry segments inside aviation with respect to their outsourcing practices and experiences. In parallel, the geographical reach of the case studies could be expanded to other areas in Europe, the USA, and Asia.

In future research, it would be interesting to compare the now analyzed developments in the outsourcing of aviation technical services with those of other industries where outsourcing may have further matured. Similar development patterns could also be expected in aviation.

\section{Conclusions}

This research concerning the outsourcing of aviation technical services was conducted by comparing real-life case examples to the findings in the literature and organizing the findings using the CIMO decision framework. Additionally, many new observations were revealed through case studies and interviews. The use of the Delphi method worked well in the quest to find opinions and experiences and not just comments on statements formed from findings in the literature.

For practical purposes, this paper provides new dimensions to design and implement outsourcing processes in the aviation industry. A wider knowledge base supported by the empirical experiences of others enables industry actors to better plan for efficient ways to carry out their business in this field. In practical terms, the results could be used by both operators and service providers in comparing own processes to industry standards and preparing for future developments. Potential new entrants to the aviation technical services outsourcing business segment can also use the findings as one element in evaluating their planned approach against established industry practices.

\section{References}

Al-kaabi, H., Potter, A., \& Naim, M. (2007). Insights into the maintenance, repair and overhaul configurations of European airlines. Journal of Air Transportation, 12(2), 27-42.

Ali-Marttila, M., Marttonen-Arola, S., Kärri, T., \& Pekkarinen, O. (2016). Understand what your maintenance service partners value. Journal of Quality in Maintenance Engineering, 23(2), 144-164. https://doi.org/ 10.1108/JQME-08-2016-0035

Bazargan, M. (2016). Airline maintenance strategies-In-house vs. outsourced-An optimization approach. Journal of Quality in Maintenance Engineering, 22(2), 114-129. https://doi.org/10.1108/JQME08-2015-0038

Beaumont, N. (2006). Outsourcing in Australia: The vendor's perspective. Department of Management Working Paper Series, Monash University, Business and Economics Working Paper 25/06, August. https://doi.org/10.1108/01443570410541993

Canaday, H. (2009). Give and take. Airline Procurement, February 2009.

Cao, Q., \& Wang, Q. (2007). Optimizing vendor selection in a two-stage outsourcing process. Computers \& Operations Research, 34, 3757 3768. https://doi.org/10.1016/j.cor.2006.01.013

De Jong, A., \& Smit, K. (2019). Collaboratives to improve industrial maintenance contract relationships. Journal of Quality in Maintenance Engineering, 25(4), 545-562. https://doi.org/10.1108/JQME-07-20130050

DeCuir-Gunby, J.T., Marshall, P.L., \& McCulloch, A.W. (2011). Developing and using a codebook for the analysis of interview data: An example from a professional development project. Field Methods, 23(2), 136-155. https://doi.org/10.1177/1525822X10388468

Demirtas, O. (2013). Evaluating the core capabilities for strategic outsourcing decisions at aviation maintenance industry. ProcediaSocial and Behavioral Sciences, 99, 1134-1143. https://doi.org/10. 1016/j.sbspro.2013.10.587 
Erickson, S. R., Marafioti, R. J., \& Summerour, R. (1997). Aviation maintenance contract management: A survey of defense and commercial practices. Logistics Management Institute, LG603T1, November 1997.

European Aviation Safety Agency. (2017). Regulations. Retrieved April 2, 2018, from https://www.easa.europa.eu/regulations

Fournel, J. L. (2005). Fixing it in Europe. Aircraft Economics, May/June, Issue $81,22-26$.

Goncalves, C. D., \& Kokkolaras, M. (2018). Collaborative product-service approach to aviation maintenance, repair and overhaul. Part I: Qualitative model. Journal of Aviation Technology and Engineering, 8(1), 20-30. https://doi.org/10.7771/2159-6670.1181

Goncalves, C. D., \& Kokkolaras, M. (2019). Collaborative product-service approach to aviation maintenance, repair and overhaul. Part II: Numerical investigations. Journal of Aviation Technology and Engineering, 8(2), 8-23. https://doi.org/10.7771/2159-6670.1182

Groenewald, T. (2004). A phenomenological research design illustrated. International Journal of Qualitative Methods, 3(1), 42-55. https://doi. org/10.1177/160940690400300104

Holkeri, J. (2019). Outsourcing of aviation technical services: A literature survey. Journal of Quality in Maintenance Engineering, 26(1), 33-52. https://doi.org/10.1108/JQME-11-2017-0079

Hsu, C. C., \& Liou, J. J. H. (2013). An outsourcing provider decision model for the airline industry. Journal of Air Transport Management, 28, 40-46. https://doi.org/10.1016/j.jairtraman.2012.12.009

Knotts, R. M. H. (1999). Civil aircraft maintenance and support fault diagnosis from a business perspective. Journal of Quality in Maintenance Engineering, 5(4), 335-348. https://doi.org/10.1108/ 13552519910298091

Lietz, P. (2010). Research into questionnaire design: A summary of the literature. International Journal of Market Research, 52(2), 249-272. https://doi.org/10.2501/S147078530920120X

Linstone, H. A., \& Turoff, M. (2002). The Delphi method, techniques and applications (pp. 3-6). Addison-Wesley. https://doi.org/10.1016/01609327(76)90011-9

Machado, M. C., Araújo, G. E., Aparecida, M., Urbina, S., \& Macau F. R. (2016). A qualitative study of outsourced aeronautical maintenance: The case of Brazilian organizations. Journal of Air Transport Management, 55, 176-184. https://doi.org/10.1016/j.jairtraman.2016.04.013
McFadden, M., \& Worrells, D. (2012). Global outsourcing of aircraft maintenance. Journal of Aviation Technology and Engineering, 1, 6373. https://doi.org/10.5703/1288284314659

Quinlan, M., Hampson, I., \& Gregson, S. (2013). Outsourcing and offshoring aircraft maintenance in the US. Implications for safety. Safety Science, 57, 283-292. https://doi.org/10.1016/j.ssci.2013.02.011

Quinlan, M., Hampson, I., \& Gregson, S. (2014). Slow to learn: Regulatory oversight of the safety of outsourced aircraft maintenance in the USA. Policy and Practice in Health and Safety, 12(1), 71-90. https://doi.org/10.1080/14774003.2014.11667798

Sheehan, B. G., Bliss, T. J., \& Depperschmidt, C. L. (2018). Enhanced, risk-based FAA oversight on Part 145 maintenance practices: A qualitative study. Journal of Aviation Technology and Engineering, 7(2), 32-41. https://doi.org/10.7771/2159-6670.1167

Sivelius, D. (2001). The Delphi method-Theoretical base for use of Delphi method. University of Turku. Retrieved October 17, 2015, from http://www.tulevaisuus.fi/topi/topi_vanha/kokohakemistosivut/ kokodelfoi.htm

Tenhiälä, A. (2011). Contingency theory of capacity planning: The link between process types and planning methods. Journal of Operations Management, 29(1-2), 65-77. https://doi.org/10.1016/j.jom.2010.05. 003

Van Aken, J. E., Denyer, D., \& Tranfield, D. (2008). Developing design propositions through research synthesis. Organization Studies, 29, 393-413. https://doi.org/10.1177/0170840607088020

Van Wagner, K. (2007). Cutting costs and cutting corners-The safety risks associated with outsourcing aircraft maintenance and the need for effective safety oversight by the Federal Aviation Administration. Journal of Air Law \& Commerce, 72(3), Article 7.

Weston, C., Gandell, T., Beauchamp, J., McAlpine, L., Wiseman, C., \& Beauchamp, C. (2001). Analyzing interview data: The development and evolution of a coding system. Qualitative Sociology, 24(3), 381400. https://doi.org/10.1023/A:1010690908200

Williams, C. (2007). Research methods. Journal of Business \& Economic Research, 5(3), 65-72. https://doi.org/10.19030/jber.v5i3. 2532

Yang, D. H., Kim, S., Nam, C., \& Min, J. W. (2007). Developing a decision model for business process outsourcing. Computers \& Operations Research, 34, 3769-3778. https://doi.org/10.1016/j.cor. 2006.01.012 


\section{Appendix 1. Aviation Technical Services (MRO) Outsourcing Case Questionnaire}

Please describe this MRO outsourcing case and/or comment in the provided summary from your point of view.

a. Scope of the outsourcing

b. Agreement duration, volume

c. Magnitude of financial implications to both operator and service provider

d. Process to select the service provider (e.g., competition or negotiation process)

Please compare this case in general with common trends in aviation MRO outsourcing.

a. Is the general trend of growing outsourcing portion felt in your segment?

b. Is cost reduction the main driver to outsource?

c. What are the alternatives to outsourcing in order to reduce costs?

d. Has outsourcing actually reduced costs?

e. Has the cost reduction been achieved by compromising other key areas?

f. Are there (perceived or real) limits in the scope and extent of outsourcing?

g. To which extent are the possible limits coming from factors outside of the basic industrial logic (such as politics, security of supply, military independence need, etc.)?

h. Have other possible targets than cost reduction been realized through outsourcing?

i. How is the relationship between operators and MRO providers developing in the future?

Please analyze the tender documentation or other requests for quotation in this case.

a. Description of the rationale for outsourcing

b. Openly indicated selection criteria and their weights

c. Key performance indicators for successful service

d. Unclear or contested requirements
Please compare this case with common trends in aviation MRO outsourcing supplier selection criteria.

a. What are the key success factors (KSFs) in MRO outsourcing?

b. What are the key criteria for MRO service provider selection?

c. Are the expectations and boundary conditions usually clear to buyers and contractors?

d. What weights are given in MRO supplier selection to cost, risk, security of supply, partnership, politics/ nationality, sustainability, business, and environment/culture?

e. How have the criteria and their weights developed in history?

f. How will the criteria and their weights develop in the future?

g. What are the relationships between objective and subjective criteria?

Please describe your MRO provider selection process.

a. Process structure? One/two-step? Formal/negotiating? Directed/restricted/open?

b. Is there a mathematical process (more than just giving and summing points per criterion, e.g., taking into account interrelationships between criteria)?

c. How good are the processes to pick the "right" contractor and to control it?

d. Are the processes and their results documented well and communicated openly?

e. What are the development actions to processes?

f. How have the processes evolved and what steps are expected in the future?

What factors guide the planning of the MRO provider selection process and selection criteria (e.g., fleet size, fleet mix, business model, ownership of fleet, and age of fleet)?

a. How similar are the processes of different operators?

b. What are the guiding parameters to process planning? 


\section{Appendix 2. Interviewees' Second Delphi Round Input Compared to First-Round Findings}

$\mathrm{MH}, \mathrm{MT}$ and AL refer to individual respondents in each of the three industry segments.

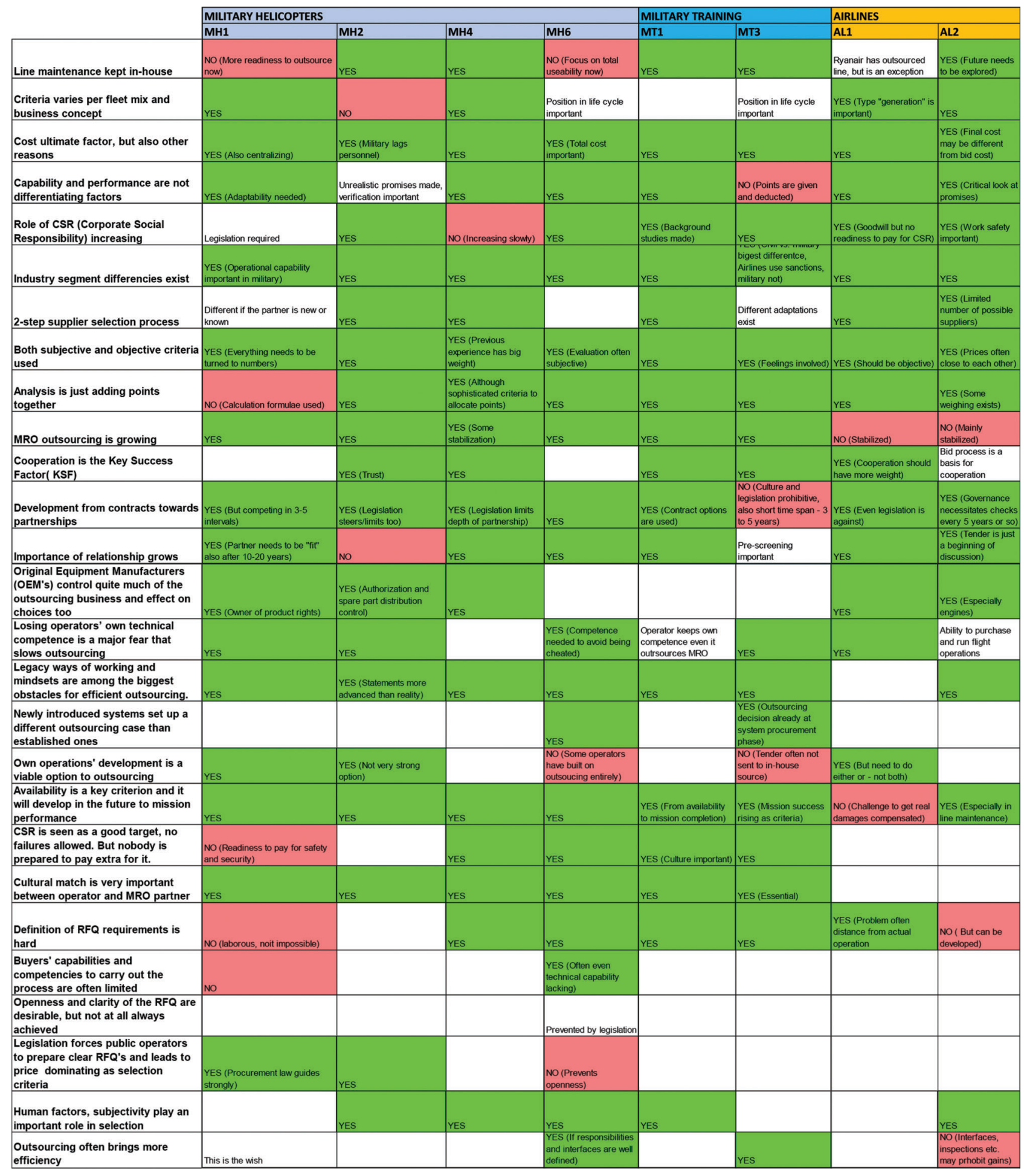

